\title{
DUAL CAREER SUPPORT ACTIVITIES OF HIGH-PERFORMANCE STUDENTS-ATHLETES IN THE PROJECT “MORE THAN GOLD”
}

\author{
Ilvis Abelkalns ${ }^{5}$, Laura Capranica ${ }^{1,8}$, Mojca Doupona ${ }^{1,6}$, Anda Paegle ${ }^{5}$, \\ Janis Stonis ${ }^{5}$, Ugis Bisenieks ${ }^{5}$, Antonio Sánchez-Pato ${ }^{7}$, \\ Francisco José Cánovas-Álvarez ${ }^{7}$, Juan Alfonso García-Roca7, \\ Alejandro Leiva-Arcas ${ }^{7}$, Lourdes Meroño ${ }^{7}$, Raquel Vaquero-Cristóbal7, \\ António J. Figueiredo ${ }^{3}$, Hugo Sarmento ${ }^{3}$, Vasco Vaz ${ }^{3}$, \\ Liliana-Elisabeta Radu², Cristian-Mihail Rus², Oana-Mihaela Rusu², \\ Barbara Ghinassi ${ }^{4}$, Pascal Izzicupo ${ }^{4}$, Angela Di Baldassarre ${ }^{4}$ \\ ${ }^{1}$ European Athlete as Student Network, Malta \\ 2 University "Alexandru Ioan Cuza" of Iași, Romania \\ ${ }^{3}$ University of Coimbra, Portugal \\ ${ }^{4}$ University "G. D'Annunzio" of Chieti-Pescara, Italy \\ ${ }^{5}$ University of Latvia, Latvia \\ ${ }^{6}$ University of Ljubljana, Slovenia \\ ${ }^{7}$ Catholic University of Murcia - UCAM, Spain \\ ${ }^{8}$ University of Rome Foro Italico, Italy
}

\begin{abstract}
One of the European Union's (EU) priorities in sports is the holistic development of athletes through combining high-performance sports with higher education. Within the ERASMUS+Sport Collaborative Partnership "More than Gold" (MTG, 603346-EPP-1-20181-LV-SPO-SCP), the aim of the empirical research was to clarify and analyse the opinions of high-performance athletes of five Member States on the opportunities for Dual Career (DC) implementation as well as support provision for high-performance athletes within their DC implementation. Survey as the research method was chosen applying questionnaire, interview and focus-group discussion as data collection methods. The research sample included in this work comprised 284 athletes.

The data obtained revealed the challenges related to overlapping schedules, long distance from the university to the training venue, and the lack of understanding and flexibility from the academic staff, which was especially challenging in the first academic year. The respondents appreciated the support of DC tutors. Finally, the opinion of experts allowed to identify 9 aspects to be implemented within the DC perspective (e. g., access to educational facilities, tutorship, psychological support). Findings urge to implement DC programmes at higher education institutions (HEIs) comprising DC guidance, flexible study and training
\end{abstract}


schedules, customized curricula, distance learning, proximity of training facilities and sports services, psychological and career support services tailored for elite-athletes. Therefore, the More Than Gold Guidelines for HEIs are crucial for the development of the European DC culture.

Keywords: Dual career, Dual Career Tutor, higher education institutions, high-performance athlete, support provision.

\section{Introduction}

Talented athletes may achieve outstanding sport performances through a long-term developmental process alongside with the academic and psycho-social development (Wylleman \& Reints, 2010). In considering the difficulty to combine the demands of elite sport with the challenges and constraints of education (e. g., dual career, DC), a high proportion of European youth talented athletes are at risk of sport or academic dropouts (Amsterdam University of Applied Sciences et al., 2016; European Commission, 2012). In fact, elite athletes might not fully realize that a sporting career does not guarantee a lifetime well-paid position and that a wise plan for post-sport is necessary (Surujlal, 2016). Conversely, educated athletes not only could be considered positive role models of full commitment towards excellence, but also prepare a smooth transition to the labour market upon the completion of a sporting career (European Commission, 2007, 2012). In line with the goals of the European strategy on prevention of early school leaving, more graduates in higher education, higher employability, increase of economic activity of citizens, and making sport policies more efficient by keeping high-performance athletes in the sport system, the European Parliament, the Council of the European Union, and the European Commission have supported the athlete's right to combine sport and education by envisaging key messages for policy makers and by providing practical tools for DC stakeholders to strengthen the dialogue between the sport bodies and educational institutions (Council of the European Union, 2017, 2020; European Commission, 2007, 2011, 2012, 2013, 2020). In particular, to foster the cooperation between Member States, to facilitate the sharing of local/national best practices in bridging the gap in DC policies and provisions, the European Commission allocates funds for ERASMUS + Sport Partnerships (European Commission, 2020).

Member States have full rights in sport and education so that different DC approaches and support services are in place at national level, ranging from State-centric regulations to laissez- faire no formal structure (Aquilina \& Henry, 2019). In addition to the existing sport-related differences in organisational structures and rules to organize clubs, competitions, and 
championships, within and between Member States differences are present also at educational level, despite the Bologna Process and the European community Action Scheme for the Mobility of University Students (ERASMUS) structured European cooperation by supporting student, teacher, and staff mobility, and calling for uniformity of accreditation, duration of degrees, organization of academic years, curricula content and teaching methods, credit transfer and accumulation system (ECTS), and service provision (Brooks, 2021, Capano \& Piattoni, 2011; European Commission, 2016). To complicate this heterogeneous context, European higher education institutions (HEIs) do not have either a common understanding of DC or structured policies and services for elite athletes (Amsterdam University of Applied Sciences et al., 2016).

To overcome existing DC practices frequently based on individual initiatives of empathic academic staff rather than on the structured guidelines on support provision (Guidotti et al., 2014), five European HEIs from State-centric regulations (e. g., University of Coimbra, Portugal; and UCAM Catholic University of Murcia, Spain), State as sponsor/facilitator (e. g., University of Latvia, Latvia) and laissez-faire no formal structure (e. g., University "G. D’Annunzio" of Chieti-Pescara, Italy; and University "Alexandru Ioan Cuza" of Iași, Romania) engaged in the More Than Gold (MTG) ERASMUS + Collaborative Partnership (603346-EPP-1-2018-1-LVSPO-SCP). In particular, MTG aimed to collect best practices and support provisions (i. e., career centre services, psychologist services, mentoring programmes for students, etc.) and student-athletes' needs for developing guidelines for HEIs, especially in the countries where DC policy is at an early development stage. To achieve the overall MTG objective, a sound analysis and interpretation of the student-athletes' and HEI experts' perception of DC challenges, support programmes, and significant stakeholders was deemed relevant. Based on relevant DC literature, the experimental approach of MTG encompassed multiple qualitative data collection methods (e. g., interviews, focus-group discussions, online questionnaires) and a purposeful recruitment of student-athletes and European HEI experts (Aquilina, 2009; Abelkalns, 2014; Conde et al., 2021; Creswell, 2009; Guidotti, Cortis, Capranica, 2015; Hunter \& Brewer, 2007; Izzicupo et al., 2021, Sánchez-Pato et al. 2017; Stambulova \& Wylleman, 2019). Specifically to this work, 284 student-athletes were included in the experimental sample. In this framework, it has been hypothesized that an online survey could provide insights on the influential factors for the implementation of DC at HEIs from student-athletes enrolled in the MTG Universities. 


\section{Methodology}

\section{Experimental Approach to the study}

Throughout the study, all procedures involving human participants performed were in accordance with the ethical standards of the institution and with the 1964 Helsinki declaration and its later amendments or comparable ethical standards (Geske \& Grīnfelds, 2006; Kristapsone, 2008). In considering that the present study involved student-athletes as experts in DC who regularly share this information and knowledge through consultation, teaching or public speaking, or publications and written reports, no approval from the Committee of the Protection of Human Subject (CPHS) was required. Furthermore, the student-athletes' opinion was related to the external topic of factors deemed relevant for dual career policies and services, not including demographic queries about income or other personal information. Participation was voluntary and signed informed consent was assumed with subjects' compilation of the online questionnaire. To meet the standards of general data protection regulations and safeguarding privacy rights of personal data according to country-specific regulations, the MTG partners were required to send to the athletes representing their HEI a pre-notification email providing information on the link to the MTG online questionnaire. To increase response rates for online questionnaires, three follow-up contacts with a fifteen-day in between have been planned (Deutskens et al., 2004). However, in being a not-list-based survey this procedure did not allow calculation of the probability and response rates (Callegaro, Manfreda \& Vehovar, 2015). The rights and welfare of research participants have been protected at all times, ensuring and maintaining confidentiality throughout the research, and allowing opting out at any time without providing any reason. For the above reasons, the approval of an Institutional Review Board (IRB) was not required. Finally, to undermine the probability of the researchers' personal impact in the process of both data collection and interpretation, the research team maintained a neutral and objective attitude (Kristapsone, 2008).

\section{The instrument}

The questionnaire encompassed 30 questions organized in four sections to gather information on: 1$)$ socio-demographic aspects $(n=12$; e. g., gender, age, practiced sport, number of years of practice, competitive level and best athletic achievement, number of training daily and weekly training sessions, academic level and major, financial support for academic studies, academic financial support); 2 ) personal objectives ( $n=6$; e. g., main reasons for enrolling at HEI, academic objectives, sports objectives in the following 5 years and the next steps to achieve them, expectations after 
graduation, relevant DC supporter); 3) needs to achieve the sport objectives ( $n=3$; e. g., main needs and related solutions, relevant stakeholder to support solutions); and 4) needs to achieve academic objectives ( $n=9$; e. g., reasons for choosing their academic major, who supported their choice, expectations from a degree in pursuing a sport/professional career, DC academic support, academic difficulties as student-athletes, teaching tools used to support DC, DC management problems and solutions, DC support providers, expected implementation at university level. Additional four questions were addressed only to student-athletes having a DC tutor, specifically related to the actual benefits, expected support, means and frequency of communication. To collect data on a large sample of a heterogeneous student-athlete population, close-ended questions were chosen (e. g., dichotomous and single or multiple response checklist type). For the relevance of the individual questions of group 2, a 10-point Likert-type scale (lowest value $=1$; highest value $=10$ ) was used.

\section{Data analysis}

The coding process was executed relatively to the age of the respondents (e. g., < 22 years vs > 23 years), the athletic level (e. g., international vs national), and the presence or absence of a DC tutorship (e. g., tutor vs no-tutor). Quantitative analysis encompassed descriptive statistic (SPSS Inc., Chicago Illinois).

\section{Results}

The purposeful recruitment of the student-athletes enrolled at the HEIs involved in the project included a total of 284 student-athletes ( $F=48 \%$, $M=52 \%$ ), competing in individual (44\%) and team (56\%) sports at international (e. g., Olympic Games, World Championships, World Cups, European Championships, Universiades, 45\%) and national (55\%) levels. Ranging in age from 19 to 28 years (overall mean 22.4), the respondents were mainly enrolled at bachelor's (80\%), with significant $(<0.05)$ lower percentages at master's (19\%), doctoral (1\%) levels. $(<22$ years: 56\%; > 23 years: 44\%) and the presence or absence of a DC tutorship (tutor: $37.1 \%$, no-tutor: $62.9 \%$ ).

The main reason (94\%) for choosing the academic major was related to the specific programme expected to provide knowledge and skills within the specific field of personal interest. Indeed, obtaining a university degree was considered very relevant (78\%), with female student-athletes attributing more frequently an importance to the acquisition of a university degree (84\%) and new knowledge and skills (94\%) with respect to their male counterparts (university degree: $72 \%$, new knowledge: 76\%). Whilst 
the majority of elite athletes (80\%) valued the achievement of a university degree, the majority of those competing at regional level (87\%) selected a particular HEI with the aim to receive financial support for studies and sport. The necessary to acquire knowledge and skills presented a difference emerged also for the student-athletes having tutor support (90\%) when compared to those not having such an opportunity (77\%). Finally, 37\% of the youngest subgroups declared that they enrolled in a university programme to be supported at sport level for achieving a higher athletic level.

Regarding the student-athletes' academic plans for the following five years, the findings confirmed that education is considered important (88\%), with female respondents planning to improve their grades $(77 \%)$ ad to continue their studies at graduate level (86\%) more frequently with respect to their male counterparts (grade improvements: $68 \%$, study continuation: 67\%). Finally, academic achievement resulted very important for athletes older than 23 years of age (78\%). For future sport achievements, differences emerged also for sport typology, with the majority (58\%) of the athletes competing in individual sports having expectations to qualify for the international competitions, whereas only 33\% of team sports declared such an expectation. Independently for an actual tutorship provision, respondents declared high expectations to improve their professional sport position (70\%), particularly athletes older than 23 years of age demonstrated the willingness to qualify for international events (57\%) and achieve top-level performances $(69 \%)$. The identification of steps to be taken for achieving the academic and sport objectives, independently from age, gender, and sport typology, student-athletes considered flexible schedules at academic and sport levels their main priority (88\%), followed by the opportunity to have access to high quality education in combination with sports (87\%). Actually, academic achievement resulted more important for student-athletes enrolled at Master's level with respect to their undergraduate counterparts. A similar picture emerged for student-athletes receiving a tutor support with respect to those who did not have this opportunity.

The respondents' opinion on the possible DC supporters substantiates the crucial role of the family (91\%) followed by that of the coaches (81\%) and professors (67\%) respectively. Conversely, lower DC supportive role was declared for the deans (34\%) and directors (37\%). Whilst almost half of female respondents (49\%) considered relevant the support of a DC tutor, only $33 \%$ of male respondents found it crucial for achieving their academic and sport objectives (33\%). Despite only 11\% considered marginal the role of a DC tutorship, just $38 \%$ of the respondents declared that they already benefit from a DC tutor. In relation to the sport typology, a tutorship support was appreciated more among team sports athletes (44\%) with respect to their individual sports counterparts (36\%). Compared to $40 \%$ individual 
sports athletes, team sports athletes also showed that the support of the club's president was important for them (46\%), Master's students were more likely to appreciate the support of their professors $(78 \%)$ and tutors (54\%), whereas Bachelor's students showed a lower acknowledgment (63\% and $37 \%$, respectively).

Table 1 summarizes the main needs student-athletes in relation to the sport typology and the availability of a DC tutor. Whilst team sport student-athletes indicated appropriate sports facilities close to the faculty and the time and space for relaxing and recovery as the most important needs, student-athletes competing in individual sport reported financial support for travelling to international competitions and flexible training schedules. In general, student-athletes supported by a tutor presented lower frequency of occurrences of needs with respect to their counterparts having no DC tutorship. Respondents' potential solutions to their needs encompass academic flexibility (58\%), good communication between the sports bodies and the HEIs (56\%) and sponsorships (55\%). Especially athletes with no tutor and those competing in individual sports envisaged to manage DC by training in the HEI facilities (41\%) and having flexible academic schedule (64\%). Furthermore, student-athletes expected to receive the support from HEI decision-makers (65\%); coaches (38\%) and the president of the sports club (33\%). Differences for sport typology emerged, with student-athletes competing in individual sports valuing more the DC support from their coach (48\%) with respect to their team sports counterparts (30\%). Overall, student-athletes declared to be strongly motivated to accomplish the academic path (62\%) adding values to their sports career (49\%), which were selected also in considering consultation with their family (49\%), the university location (36\%), its prestige (33\%), and its connection with prestigious sports clubs (70\%). In particular, the possibility to engage in something new and challenging for was appreciated (35\%), with individual sport athletes (41\%) and the student-athletes receiving no DC tutorship (36\%) welcoming interactive activities. In fact, the respondents pointed out that DC could improve their theoretical and practical knowledge also related to their sport (69\%), and their communication skills (51\%). Furthermore, the student-athletes appreciated the opportunity to participate in international and national university competitions (36\%). For possible implementation of DC at HEIs, respondents envisaged extra exam sessions (44\%), justification for missing classes (41\%) and opportunity to participate in national and international competitions (39\%), with athletes competing at regional level (30\%) considering important study grants and study abroad opportunities. Due to demanding sport constraints (e. g., competitions, training camps and training sessions), high-performance athletes reported difficulties in attending theoretical and practical lessons 
(66\%) and voluntary activities organized by the university (52\%), as well as a lack of time for preparing home assignments (45\%). Despite the majority of student-athletes had access to digital academic materials (72\%) and on-line educational resources (45\%), more interactive digital resources, DC support provision (73\%), and collaboration with coaches (45\%) were envisaged. In general, individual sport athletes (61\%), undergraduate students (53\%) and athletes with no tutorhip (60\%) expect DC to be recognized and implemented through DC centres. Finally, the 107 respondents declaring to benefit from DC tutorship (Latvia: $n=6$, Spain: $n=43$, Romania: $n=46$ and Portugal: $n=12$ ) deemed relevant an extensive communication with their tutors on how to access to courses (41\%) and flexibility for examination (41\%) and attendance (40\%), counselling on courses (36\%) and learning paths $(36 \%)$, information on how to contact teachers $(33 \%)$, to solve administrative issues (33\%), to manage exam calendar (31\%), and usage of virtual campuses $(22 \%)$.

Table 1. The needs in sport of high-performance athletes from different groups

\begin{tabular}{|l|c|c|c|c|}
\hline Statement & $\begin{array}{l}\text { Team sport } \\
\text { (\%) }\end{array}$ & $\begin{array}{l}\text { Individual } \\
\text { sport (\%) }\end{array}$ & $\begin{array}{l}\text { Have Tutor } \\
\text { (\%) }\end{array}$ & $\begin{array}{l}\text { Have no } \\
\text { Tutor (\%) }\end{array}$ \\
\hline $\begin{array}{l}\text { Appropriate sports facilities } \\
\text { close to the faculty }\end{array}$ & 54 & 62 & 43 & 59 \\
\hline $\begin{array}{l}\text { Time and space for relaxing } \\
\text { and recovery after the } \\
\text { physical effort }\end{array}$ & 54 & 64 & 53 & 63 \\
\hline $\begin{array}{l}\text { Financial support for } \\
\text { travelling to international } \\
\text { competitions }\end{array}$ & 59 & 37 & 58 & 41 \\
\hline $\begin{array}{l}\text { A flexible schedule for } \\
\text { training }\end{array}$ & 64 & 53 & 49 & 64 \\
\hline
\end{tabular}

\section{Discussion}

The present findings of the More Than Gold (MTG) ERASMUS + Collaborative Partnership (603346-EPP-1-2018-1-LV-SPO-SCP) extended the information gathered during national focus groups (Capranica et al. submitted) on European elite student-athletes' view on possible implementation of DC at HEI level based on their actual experience at five European HEIs from State-centric regulations (e. g., University of Coimbra, Portugal; and UCAM Catholic University of Murcia, Spain), State as sponsor/facilitator. Thus, this study allows for further tentative speculations in the establishment of European guidelines for the implementation of DC at HEI level. 
Despite the fact that 284 respondents declared a high athletic level and a long elite sport career, only $38 \%$ of them declared to receive the support of a DC support, corroborating the inappropriateness of considering the DC of European athletes in general terms and the need of further implementation of DC tutorship programmes at HEI levels (Condello et al., 2019; Sánchez-Pato et al., 2017; Conde et al. 2021). Furthermore, the differences emerging for type of sport, athletic level, age and gender in the perceived student-athletes challenges of pursuing a higher degree substantiate the need of a harmonized approach to DC at HEI level to help this special population maintaining the motivation towards an academic career, especially at the start of the undergraduate degree path (Aquilina, 2013; Condello et al., 2019; Gaston-Gayles \& Baker, 2015; Guidotti \& Capranica, 2013; Lupo et al., 2012, 2015; Ryba, Ronkainen, N. J., \& Selänne, 2015). Indeed, DC is particularly challenged when athletes face the transition from high school to higher education, which also coincides with the increased demands and commitment when transitioning from youth to senior sport categories (Stambulova \& Wylleman, 2019). This peculiar stage leads to long absences from home due to the increased training volume, which could conflict with motivation to study. Thus, mentoring is necessary to prevent early school leaving in line with the Europe 2020 strategy (LópezFlores et al., 2020). Despite student-athletes progressing towards graduation or enrolled in graduate programmes could be more skilled in managing their academic and sport commitments, the participants in this study indicated DC centres and tutoring as crucial for counselling individual academic paths necessary to prevent conflicting demands with the sport calendar, and in helping practical arrangements in the academic schedules during frequent travelling periods to compete at national and international level (Sánchez-Pato et al., 2017). Provided that different sports disciplines require specific training and competition schedules, facilities, and locations (especially environmental sports), universities shall offer different adjustments, lectures, and tutoring for their student-athletes (Amsterdam University of Applied Sciences et al., 2016). In particular, the participants in this study called for a DC implementation encompassing flexibility and tailored curricula, and specific services (career counselling, sports facilities, distance learning). In this respect, the educational models based on a DC pedagogical approach could be considered (Lapland University of Applied Sciences et al., 2017; Sánchez-Pato et al., 2017).

The present findings are substantiated in the literature on the need of a coherent support network to manage the DC challenges in different contexts (Amsterdam University of Applied Sciences et al., 2016; Condello et al., 2019; Li \& Sum, 2017; Storm et al. 2021). In fact, the student-athletes' view on the needed DC implementation call for a collective effort and 
regular communication across the athlete's sport and education entourage for achieving both sport and academic goals. Interesting to note, the participants in this study declared to be enrolled in a variety of university majors based on individual attitudes, the prestige and location of the university, and the prestige and location of their sport club (Foster \& Huml, 2017). Furthermore, some of them really appreciated the opportunity to compete for their HEI in national and international university championships, which further corroborate a promising alliance between sport and education. Indeed, also HEIs could consider student-athletes as valuable resources when representing them in sport and public events, as well as role models or ambassadors for promoting activities or fund-raising (Harrison \& Lampman, 2001).

In considering the peculiarities of higher education and sport systems in the Member States, HEIs could contribute to the development of a European DC discourse by engaging in an effective dialogue with other educational institutions and sport bodies through the European Athlete as Student (EAS) network, which fosters cross-national cooperation through the exchange of DC best practices in a shared European DC vision at local, National, and EU levels (Capranica et al., 2021; Guidotti, Cortis \& Capranica, 2015; Stambulova \& Wylleman, 2019). In particular, this dialogue could contribute to the establishment of European DC guidelines for HEIs, which is necessary to guide the holistic development of student-athletes in their transition from high school to university and during their academic path towards the accomplishment of a university degree.

\section{Conclusions}

In applying a qualitative approach to the identification of areas for DC implementation at HEI level based on the views of student-athletes enrolled at universities with different dual career policies, the present findings contributed to the eminence-based knowledge for the development of the European DC guidelines for HEIs. However, this relevant information should be integrated with that collected from HEI experts, who could expand our knowledge on alternative objectives and efficient allocation of resources to guarantee university student-athletes positive academic experiences and effective support towards the achievement of a degree. Based on the present findings, the following key conclusions could be addressed:

- Athletes tend to enrol in higher education aiming to acquire knowledge and skills to pursue graduate studies and/or higher sports achievements, unless conflicts between academic and sports commitments arise. 
- Athletes tend to choose their academic path based on the prestige and location of the HEIs and/or the sports clubs.

- Student-athletes need a coherent supportive environment encompassing family and coaches, as well as teachers, classmates and teammates, who should be empowered through a DC education.

- HEIs should provide DC centres encompassing DC programmes based on educational models and tutorship tailored on the needs of the student-athletes, e-learning, financial support and availability of sports facilities.

- Student-athletes receiving the support of a tutor are more motivated to pursue a DC path, being helped in getting acquainted with the academic environment, in managing daily schedules, and in handling conflicts between academic and sport commitments.

- Scholarships and/or financial support for student-athletes are envisaged to lessen their academic and sport economic burden.

- Whilst a lack of qualitative sports facilities close to the HEIs could negatively affect the DC of athletes, in improving their own sports facilities HEIs could enhance their DC services, increase their prestige as well as their financial revenues.

- HEIs should publicize the student-athletes' achievements, thereby raising a DC awareness in the academic community and in the society at large. Furthermore, through their student-athletes, HEIs could increase their visibility and prestige.

- Some Consortium team universities, for instance, the University of Latvia and University degli Studi G. d' Annunzio Chieti-Pescara do not provide a sports tutor as an official position. At the Alexandru Ioan Cuza University (Romania), there is no athlete tutor, but only a group tutor working with selected categories of students.

- The information gathered during the MTG project (603346-EPP1-2018-1-LV-SPO-SCP) determined the introduction of a DC programme in two partner universities, supporting the feasibility of DC implementation at HEI levels also in Member States with no formal structure in place.

\section{Aknowledgment}

This work was supported by the European Commission under the Erasmus + Programme [number 603346-EPP-1-2018-1-LV-SPO-SCP SCP]. The funders had no role in study design, data collection and analysis, decision to publish, or preparation of the manuscript. 


\section{References}

Abelkalns, I. (2014). Augstas klases sportistu duālās karjeras vadība Latvijas augstskolās. (Dual career management of High-performance Athletes in Latvian universities). Latvijas Universitāte, Riga.

Amsterdam University of Applied Sciences, Birch Consultants, the Talented Athlete Scholarship Scheme, the Vrije Universiteit Brussel, and European Athlete as Student Network (2016). Study on the minimum quality requirements for dual career services. Research report. Retrieved from: http://bookshop.europa.eu/is-bin/INTERSHOP.enfinity/WFS/ EU-Bookshop-Site/en_GB/-/EUR/ViewPublication-Start?PublicationKey $=$ NC0116370

Aquilina, D. A. (2009). Degrees of success negotiating dual career paths in elite sport and university education in Finland, France and the UK: a Doctoral Thesis. Loughborough (UK): University of Loughborough.

Aquilina, D. (2013). A Study of the Relationship Between Elite Athletes' Educational Development and Sporting Performance. The International Journal of the History of Sport, 30(4), 374-392. https://doi.org/10.1080/09523367.2013.765723.

Aquilina, D., \& Henry, I. (2019). Elite athletes and university education in Europe: a review of policy and practice in higher education in the European Union Member States. International Journal of Sport Policy and Politics, 2, 25-47. doi:10.1080/19406941003634024

Brooks, R. (2021). The construction of higher education students within national policy: A cross-European comparison. Compare: A Journal of Comparative and International Education, 51(2), 161-180.

Capano, G., Piattoni, S. (2011). From Bologna to Lisbon: the political uses of the Lisbon 'script' in European higher education policy. Journal of European Public Policy. 18: 584-606. doi:10.1080/13501763.2011.560490.

Callegaro, M., Manfreda, K. L., Vehovar, V. (2015). Web Survey Methodology. Thousand Oaks, California: Sage.

Capranica, L., Figueiredo, A., Ābeḷkalns, I., Blondel, L., Foerster, J., Keldorf, O., ... \& Doupona, M. (2021). The Contribution of the European Athlete as Student Network (EAS) to European Dual Career ERASMUS + Sport Collaborative Partnerships: An update (La Contribución de la Red European Athlete as Student (EAS) a las European Dual career ERASMUS + Sport: Una actualización). Cultura, Ciencia y Deporte, 16(47), 7-17.

Condello, G., Capranica, L., Doupona, M., Varga, K., \& Burk, V. (2019). Dual-career through the elite university student-athletes' lenses: The international FISU-EAS survey. PloS one, 14(10), 1-18.

Council of the European Union, (2017). Resolution of the Council and of the Representatives of the Governments of the Member States meeting within the Council on the European Union Work Plan for Sport. Brussels, 24 May 2017 (OR. en) 9639/17. https://eur-lex. europa.eu/legal-content/EN/TXT/?uri = CELEX\%3A42017Y0615\%2801\%29.

Council of the European Union (2020). Resolution of the Council and of the Representatives of the Governments of the Member States meeting within the Council on the European Union Work Plan for Sport (1 January 2021 - 30 June 2024) (2020/C 419/01).

Creswell, J. W. (2009). Qualitative inquiry and research design: choosing among five approaches. $2^{\text {nd }}$ ed., Thousand Oaks, California: Sage.

Conde, E., Meroño, L., Arias-Estero, J. L., García-Roca, J. A., Leiva-Arcas, A., CánovasÁlvarez, F. J., ... \& Sánchez-Pato, A. (2021). Percepción de la influencia del modelo Estport en la carrera dual de los estudiantes-deportistas en universidades de España e 
Italia. (Perception of the influence of the Estport model in the dual career of studentathletes in universities in Spain and Italy). Cultura, Ciencia y Deporte, 16(47), 31-37. doi:10.12800/ccd.v16i47.1623

Deutskens, E., De Ruyter, K., Wetzels, M., Oosterveld, P. (2004). Response rate and response quality of internet-based surveys: An experimental study. Mark Lett., 15(1): 21-36. doi: https://doi.org/10.1023/B:MARK.0000021968.86465.00

European Commission (2007). Commission staff document: Action plan "Pierre de Coubertin" accompanying document to the White Paper on Sport, Directorate-General Education and Culture. Brussels: EC.

European Commission (2011). Communication from the commission to the European Parlament, the Council, the European Economic and Social Committee and the Committee of the Regions. Developing the European Dimension in Sport. Brussels, 18.1.

European Commission (2012). EU Guidelines on Dual Careers of Athletes, Recommended policy actions in support of dual careers in high-performance sport. DOI: 10.2766/52683

European Commission (2013). Conclusions of the Council and of the Representatives of the Governments of the Member States, meeting within the Council, on dual careers for athletes. Official Journal of the European Union, Vol. 56, 14 June 2013., https://zarzadzaniesportem.org/uploaded_files/cke_1577706167_Conclusions_of_the_Council_and_of_ the_Representatives_of_the_Governments_of_the_Member_States_on_dual_careers_for_athletes-44f47f73-f855-4d04-a566-d3e479c4069c_4EzAr5bJtZh2.pdf

European Commission (2016). Mapping and Analysis of the Specificity of Sport. https:// ec.europa.eu/assets/eac/sport/library/studies/mapping-analysis-specificity-sport_en.pdf

European Commission (2020). ERASMUS + Project Results: Opening Minds. https:// ec.europa.eu/programmes/erasmus-plus/projects/

Foster, S. J. L., Huml, M. R. (2017). The Relationship Between Athletic Identity and Academic Major Chosen by Student-Athletes. International Journal of Exercise Science, 10: $915-925$.

Gaston-Gayles, J., \& Baker, A. (2015). Opportunities and Challenges for First-Year Student-Athletes Transitioning from High School to College. New Dir Stud Leadersh, 2015(147), 43-51. https://doi.org/10.1002/yd.20142.

Geske, A., Grīnfelds, A. (2006). Izglitïbas pētnieciba (Educational research). Rīga: LU Akadēmiskais apgāds.

Guidotti, F., \& Capranica, L. (2013). Le motivazioni verso sport, istruzione e carriera sportiva degli studenti-atleti italiani (The motivations towards sport, education and sporting career of Italian student-athletes). In A. M. Pioletti \& N. Porro (Eds.), Lo sport degli europei: cittadinanza, attività, motivazioni. Franco Angeli.

Guidotti, F., Cortis, C., \& Capranica, L. (2015). Dual career of European student-athletes: a systematic literature review. Kinesiologia Slovenica, 21: 5-20.

Guidotti, F., Lupo, C., Cortis, C., Di Baldassarre, A., \& Capranica, L. (2014). Italian teachers' perceptions regarding talented atypical students: A preliminary study. Kinesiologia Slovenica, 20(3), 36-46.

Harrison, C. K., Lampman, B. (2001), The Image of Paul Robeson: Role Model for the Student and Athlete. Rethinking History, 5: 117-130. doi:10.1080/13642520010024190.

Hunter, A. D., \& Brewer, J. (2007). Multimethod research in sociology. In: Tashakkori A., Teddlie C., editors. Handbook of mixed methods in social \& behavioral research. Nachdr. Thousand Oaks, California: Sage Publ. 
Izzicupo, P., Di Baldassarre, A., Abelkalns, I., Bisenieks, U., Sánchez-Pato, A., CánovasAlvarez, F. J., ... \& Capranica, L. (2021). Dual Careers of Athletes During COVID-19 Lockdown. Frontiers in psychology, 12, 739. https://doi.org/10.3389/fpsyg.2021.657671

Kristapsone, S. (2008). Zinātniskā pētniecība studiju procesā (Scientific research in the study process). Rìga: Biznesa augstskola Turība.

Lapland University of Applied Sciences et al. (2017). Facilitating Higher Education for Athletes - WINNER Education model: Final Report.

Li, M., Sum, R. K. W. (2017). A meta-synthesis of elite athletes' experiences in dual career development. Asia Pacific Journal of Sport and Social Science. 2017; 1-19. doi: 10.1080/21640599.2017.1317481.

López-Flores, M., Penado, M., Avelar-Rosa, B., Packevičiūtė, A., Ābeḷkalns, I., (2020). May the Mentor be with You! An innovative approach to the Dual Career mentoring capacitation. UCAM Catholic University of Murcia Publ. DOI: 10.12800/CCD. V16I47.1698

Lupo, C., Guidotti, F., Goncalves, C., Moreira, L., Doupona Topic, M., Bellardini, H., Tonkonogi, M., Colin, A., \& Capranica, L. (2015). Motivation towards dual career of European student-athletes. European Journal of Sport Science, 15(2), 151-160. https:// doi.org/10.1080/17461391.2014.940557.

Lupo, C., Tessitore, A., Capranica, L., Rauter, S., \& Doupona-Topic, M. (2012). Motivation for a dual-career: Italian and Slovenian student-athletes. Kinesiologia Slovenica, 18(3), 47-56.

Ryba, T. V., Ronkainen, N. J., \& Selänne, H. (2015). Elite athletic career as a context for life design. Journal of Vocational Behavior, 88, 47-55. https://doi.org/10.1016/j. jvb.2015.02.002.

Sánchez-Pato, A., Isiodori, E., Calderon A., Brunton J. (2017). An Innovatative European Sports Tutorship model of the Dual Career of Student-Atlhetes. Murcia: UCAM Catholic University of Murcia.

Stambulova, N. B., \& Wylleman, p. (2019). Psychology of athletes' dual careers: A stateof-the-art critical review of the European discourse. Psychology of Sport and Exercise, 42, 74-88. doi:https://doi.org/10.1016/j.psychsport.2018.11.013

Storm, L. K., Henriksen, K., Stambulova, N. B., Cartigny, E., Ryba, T. V., De Brandt, K., et al. Ten essential features of European dual career development environments: A multiple case study. Psychology of Sport and Exercise. 2021;54: 101918. doi:10.1016/ j.psychsport.2021.101918)

Surujlal, J. (2016). Influence of outlook towards work on entrepreneurial potential of professional sport coaches in South Africa. Procedia Economics and Finance, 35, 597603. https://doi.org/10.1016/S2212-5671(16)00073-3

Wylleman, P., \& Reints, A. (2010). A lifespan perspective on the career of talented and elite athletes: Perspectives on high-intensity sports. Scandinavian journal of medicine \& science in sports, 20, 88-94. 